\title{
23
}

\section{Management Technology Convergence}

\author{
Moderator: Einar STEFFERUD, First Virtual Holdings, Inc., U.S.A.
}

Historically, much of our network management technology has been characterized by a sharp focus on local enclave management, with an unstated assumption that someone owns the entire enclave of interest, so that whatever happens outside that enclave can be seen as being Someone Else's Problem (SEP). It is not surprising that our current environment is loaded with divergent technologies.

For the future, we can see that all these enclaves need to be interconnected into some kind of "internet" where no one owns the whole thing, but where the whole thing still needs to be "managed". Thus the future might be seen as full of conflicts to be resolved in some kind of convergence process.

The panelists will describe their ideas about how convergence might occur. Will it occur by itself in a free and open market? Will some benevolent vendor resolve everything for us by supplying a truly winning proprietary technology? Will some single benevolent institutional authority arise to define convergence for everyone ? Or, will convergence simply not happen? 